\section{Factors associated with stages of change for red meat and vegetable intake by Japanese-Brazilians}

\author{
Fatores associados aos estágios de mudança \\ para o consumo de carnes vermelhas, verduras \\ e legumes em nipo-brasileiros
}

\begin{abstract}
Stages of change assess individual motivation for lifestyle changes, contributing to the development of more effective intervention strategies. The objective of the present study was to identify factors associated with stages of change for lower intake of red meat and higher intake of vegetables in a cross-sectional analysis of 578 JapaneseBrazilians aged 30-90 years. In adjusted logistic regression models, the odds ratios for women $(O R=1.89 ; 95 \% C I: 1.154 ; 3.103)$ and physically active individuals (OR=1.00; 95\%CI: 1.000; 1.001) were positively associated with stage of "action" for the higher intake of vegetables. Inverse associations were observed between central obesity $(O R=0.5$; 95\%CI: 0.351; 0.887) and highest tertile of red meat intake (OR =0.50; 95\%CI: 0.302; $0.817)$, as well as a positive association between age $(O R=1.04 ; 95 \% C I: 1.020 ; 1.070)$ and the stage of "action" to the lower intake of meat were verified. Motivation for Japanese-Brazilians to change their food intake was linked to lifestyle. Stage of change is an important factor in mediating food intake behavior change.
\end{abstract}

Food Consumption; Nutritional Epidemiology; Japanese-Brazilians
Patricia Barbieri 1

Raphaela Fernanda Muniz Palma 1

Renata Yumi Nishimura 1

Renata Damião ${ }^{2}$

Marselle Bevilacqua ${ }^{2}$

Flávia Massimino ${ }^{2}$

Rita Chain 3

Suely Godoy Agostinho Gimeno 2

Sandra Roberta Gouvea Ferreira 4

Daniela Saes Sartorelli 1

Japanese-Brazilian Diabetes Study Group 5

\section{Introduction}

The relative and absolute increase in chronic non-communicable diseases reflects the intense changes in the global epidemiological profile beginning in the mid-20th century. Currently, $60 \%$ of all dysfunctions and $47 \%$ of the world disease burden result from non-communicable diseases 1 . In 2020, the world estimated prevalence of these diseases is of $57 \%$, representing three-fourths of all deaths in the world ${ }^{2}$.

The usual food consumption has been considered one of the main modifiable risk factors for chronic non-communicable diseases 2. High intake of saturated fats is known to be an important risk factor for cardiovascular diseases 2 . According to a previous study of Japanese-Brazilians, high red meat intake was associated with a 4.7-fold risk of developing metabolic syndrome, when compared to lower intake, after seven years of follow-up 3 .

Low intake of fruits and vegetable is one of the five main risk factors associated with chronic non-communicable diseases, accounting for 2.7 million deaths in the world 1. A previous study showed that a higher intake of vegetable by Japanese-Brazilians was associated with a lower chance of $60 \%$ of impaired glucose tolerance, independently of other potential confounders 4 . Due to the relevance of daily intake of fruit and vegetable for the promotion of a healthy lifestyle and prevention of diseases 2 , strategies to the in- 
creased intake of these foods have being developed worldwide 5 .

The transtheoretical model or "stages of change" assess individual motivation to change unhealthy living habits and has been used to tailor nutritional intervention studies ${ }^{6}$. Stages of change describe a sequence of cognitive and behavioral steps until reaching actual behavior changes, namely: pre-contemplation (non-recognition of the need for or interest in change), contemplation (recognition of the need for and intent to change), preparation (planning change), action (change occurring in up to six months), and maintenance (change maintained for more than six months) 7 .

A previous study, the Next Step Trial, including 1,795 individuals, showed that evolution in stages of change, or motivation, was associated with increased adherence to dietary treatment, reducing the intake of saturated fat 8 . Verification of stages of dietary change for the intake of red meat, vegetable, and their association with demographic and lifestyle factors, is essential for identifying target groups for intervention.

Since 1989, the Japanese-Brazilian Diabetes Study Group (JBDSG) has investigated the prevalence of diabetes and risk factors in a population of Japanese ancestry living in Bauru, São Paulo State, Brazil. The first cross-sectional survey, in 1993, showed a high prevalence of diabetes (22.6\%), higher than in the Japanese population in Japan. In 2000, the second cross-sectional survey included individuals over 30 years of age and showed a $78 \%$ rate of impaired glucose disturbances, considered one of the highest in the world 9 . These findings have stimulated the development of a lifestyle intervention program, as an attempt to prevent/reduce the risk of chronic diseases in this population.

The aim of the present study was to investigate the association between socio-demographic, anthropometric, morbidity, lifestyle and the individual motivation for the lower intake of red meat and higher intake of vegetable, evaluated by stages of change in a cross-sectional analysis of baseline data of 578 adult Japanese-Brazilians who participated at the Lifestyle Intervention Study. The study also investigated the feasibility of using stages of change to classify individual motivation to change food intake.

\section{Methodology}

This was a cross-sectional study using baseline data of the Lifestyle Intervention Study in the Japanese-Brazilian Population at High Risk for Metabolic Syndrome in Bauru, São Paulo. The intervention study was conducted from 2005 and 2007 with the objective of evaluating the impact of a community-based lifestyle intervention program. Invitations to participate in the study were issued to first-generation Japanese (born in Japan, or Isseis; $\mathrm{N}=1,330$ ) and second-generation (Niseis) and their family members, 30 years or older, who participated in the cross-sectional survey conducted in 2000. Individuals that agreed to participate underwent clinical, laboratory, anthropometric, and lifestyle evaluations at baseline and at 12 and 24 months of follow-up. The intervention program consisted of encouragement for weight loss among overweight individuals and promotion of physical activity and healthy eating, with goals related to the reduced red meat and high vegetale intake.

The exclusion criteria included liver disease, kidney disease, cancer, pregnant and nursing women, and cases with incomplete data on stages of change and food intake. Of the 717 individuals who underwent to the biochemical analysis, 578 answered the questionnaire on stages of change and participated in the dietary survey at baseline on the intervention study and were considered in the current study.

All the participants signed the informed consent form, and the intervention study was approved by the Institutional Review Board of the Federal University in São Paulo (UNIFESP). The current study was approved by the Institutional Review Board of the Academic Health Center of the School of Medicine in Ribeirão Preto, University of Paulo (USP).

\section{Socio-demographic and lifestyle variables}

Data on age, gender, educational level, working activities, smoking, and alcohol consumption were obtained with a structured questionnaire.

Level of physical activity was evaluated with the short version of the International Physical Activity Questionnaire (IPAQ), previously validated for the Brazilian population 10. For the current study, individuals were classified as physically active if they reported a minimum of $30 \mathrm{~min}$ utes of physical activities (vigorous, moderate, or walking) at least 5 times a week (150 minutes / week).

Food consumption was evaluated using three 24-hour food recalls. The nutrient composition of the diet was calculated using the NutWin (NutWin Software Program of Nutrition Support, 1.5 version; Escola Paulista de Medicina, São Paulo, Brazil). The nutrient database used was essentially based on the official American table (Agricultural Research Service, United States Department of Agriculture. USDA National Nutrient Database 
for Standard Reference - Release 18; http:/ /www. nal.usda.gov/fnic/foodcomp/Data/), the Brazilian Food Composition Table (TACO) 11, and a book of Japanese recipes 12 .

Dietary exposures included the intake of vegetable (all vegetables consumed raw or cooked, except potato, manioc, yam, and Chinese yam) and red meat (beef and pork, whether consumed roast, cooked, or fried).

\section{Evaluation of stages of change}

Stages of change for the consumption of red meat and vegetables were obtained by using a questionnaire adapted by Kristal et al. ? The questionnaire included items on self-perceived adequacy of red meat and vegetable usually consumed by the individuals, as well as their motivation to change their food intake. On the present study, the stages of change were categorized into "pre-action" (precontemplation, contemplation, and preparation) and "action" (action and maintenance), thereby allowing comparison with previous studies 6 . Individuals classified in "pre-action" stages have not incorporated the habits into their real behavior, although they may differ as to the cognitive perception of the benefits of change. Meanwhile, individuals in "action" and maintenance stages report practicing the habit, differing only in relation to the period in which they adopted the behavior. Classification in the stage of action for the consumption of vegetable expresses individual motivation to eat more of these foods, or the maintenance of this habit for more than six months, while classification in the stage of action for red meat intake shows individual motivation to eat less of this food group.

\section{Clinical and biochemical evaluation}

Blood samples were obtained to determine blood glucose and lipid profile (total cholesterol, fractions, and tryglicerides). Two hours after ingesting Glutol (Laborclin, Pinhais, Brazil), a second blood sample was taken to measure only plasma glucose. Individuals with capillary blood glucose $\leq 200 \mathrm{mg} / \mathrm{dL}$ or those who reported diabetes were dispensed from the glucose overload. The fasting blood sample was used to determine the measures the blood glucose and lipid profile (total cholesterol, fractions, and tryglicerides). Plasma glucose was measured with the glucose oxidase method, and lipoproteins with enzymatic kits.

Classification of impaired glucose disturbances was based on the World Health Organization (WHO) criteria 12. Dyslipidemia was defined according to the National Cholesterol Education
Program (NCEP) guidelines 14. Blood pressure was measured with an automatic blood pressure monitor (Omron model HEM-712C; Omron Health Care, Inc., USA), and hypertension was classified according to WHO guidelines ${ }^{15}$. On the present study, the diagnoses of diabetes, hypertension and/or dyslipidemia were considered as presence of morbidities.

\section{Anthropometric evaluation}

Weight $(\mathrm{kg})$ and height $(\mathrm{m})$ were measured with an electronic platform scale, model PL 180 (Filizola, São Paulo, Brazil) with a capacity of $150 \mathrm{~kg}$ to the nearest $10 \mathrm{~g}$, and an anthropometric tape fixed to the wall, respectively. These measurements were taking with individuals without shoes in light clothes. Waist circumference was measured using the midpoint between the lower rib margin and iliac crest, according to WHO guidelines 16 . Classification of central obesity was based on the waist circumference cutoff points of $90 \mathrm{~cm}$ for men and $80 \mathrm{~cm}$ for women, as recommended for the Japanese population 16 .

\section{Statistical analyses}

Distributions were calculated for the relative and absolute frequencies, median, mean, and standard deviation (SD) of the target variables. Twosided Student t-test was used to analyze mean differences food intake according to stages of change. Logistic regression models were used to investigate factors associated with stage of action for increased vegetable intake and reduced red meat intake after adjustments for gender (female/male), generation (1st/2nd), age (years), central obesity (yes/no), smoking (never smoked, former smoker, or current smoker), presence of diseases (hypertension, diabetes and/or dyslipidemia: yes/no), physical activity $\geq 150$ minutes/ week (yes/no), alcohol consumption (yes/no), and tertiles of red meat, vegetable and total energy intake.

Statistical significance was set at $\mathrm{p}<0.05$. The statistical analyses used SPSS for Windows, version 14.0 (SPSS Inc., Chicago, USA).

The study complies with the ethical principles contained in the Declaration of Helsinki (1964, revised in 1975, 1983, 1989,1996, and 2000), of the World Medical Association, and with the guidelines of the Institutional Review Board of UNIFESP. 


\section{Results}

A total of 717 first and second-generation Japanese-Brazilians participated at baseline assessment of the Lifestyle Intervention Study of the Japanese-Brazilian Population at High Risk for Metabolic Syndrome in Bauru, São Paulo State. Of these, 12 were excluded because they were of third generation and 127 given the incomplete data on stages of change or food intake.

The 578 participants were predominantly second-generation and females. Table 1 shows the high rates of disease prevalence (diabetes, hypertension, and/or dyslipidemia) and central obesity.

Mean (SD) total energy intake was 1,939 (713) $\mathrm{kcal} /$ day. Energy from macronutrient (52\% from carbohydrates, $17 \%$ from proteins, and $29.5 \%$ from lipids) and mean red meat intake (129g/ day) were adequate. However, the consumption of fruit and vegetable was lower than recommended by the WHO for prevention of chronic non-communicable diseases (400g/day) 2 .

Table 2 shows the mean intake values (SD) for red meat, fruits, vegetables, and nutrients according to stages of change for lower meat intake and increased intake of vegetables. Mean red meat intake in the used diet was reduced among individuals classified as "in action" for decreasing their meat consumption, and intake of vegetables was higher among individuals classified as "in action" for increased consumption of vegetables, suggesting that Japanese-Brazilians' self-perception of the adequacy of their intake of these foods was acurate. In addition, individuals classified in the stage of action for the reduced red meat consumption reported lower intake of energy from total fat, saturated fat, and proteins, when compared with participants in "pre-action". Likewise, individuals classified as in action for the higher consumption of vegetable reported lower intake of fat when compared with individuals in "pre-action".

Table 3 shows the odds ratios (OR) and 95\% confidence intervals $(95 \% \mathrm{CI})$ for the stage of action for increased vegetable and reduced red meat after multiple adjustment, considering the stages of change in two categories ("pre-action" and "action") as dependent variables. A positive associations were observed among women and those who reported practice of physical activity, and motivation for higher intake of vegetable. Older individuals had higher chances for the motivation to the reduced intake of red meat, when compared with younger participants. Individuals with central obesity and those who reported a higher meat consumption had $40 \%$ and $50 \%$ lower chances for motivation to the reduced red meat intake, respectively.

\section{Discussion}

In the present study, age was directly associated with a greater motivation to the reduced red meat intake. Meanwhile, individuals with central obesity and those who reported higher usual meat consumption were less motivated to improve this eating habit. As for increased intake of vegetables, women and physically active individuals were more motivated to decrease their red meat intake. The results suggest that more intensive intervention measures should be taken among male and younger individuals and those with central obesity, in order to achieve the food intake goals under the program to promote healthy lifestyles.

Given the inherent limitations of the crosssectional design and cultural specificities of food intake in the study population, extrapolation of the findings is not recommended. In addition, prospective studies are necessary to evaluate changes in food intake in relation to pre-intervention motivation.

Data from the present study showed that approximately $30 \%$ of total energy intake came from fat, suggesting a cultural adaptation by Japanese-Brazilians to the Brazilian diet, according to estimates from the 2003 Brazilian Family Budget Survey (POF 2003) 17. Meanwhile, intake of fruits and vegetables (326g/day) was lower than recommended by the WHO $(400 \mathrm{~g} /$ day) for preventing chronic non-communicable diseases 2 .

Previous studies of stages of change for food consumption adopted a pre-determined cutoff point for portion sizes to classify individuals. For example, individuals would be classified in the stage of action for fruit and vegetable if they consumed more than $400 \mathrm{~g} /$ daily of these foods 7 . In the current study, the adoption of self-perceived adequacy of consumption for red meat and vegetable, as well as for motivation to change the food intake, was conducted. This approach allows evaluating the capability of individuals on the self-classification in relation to the adequacy of intake, and suggests if providing the information about portion sizes is required in the intervention study 6 . We found that self-classified adequacy of intake for red meat and vegetable was adequate since individuals in the stage of action for the reduced red meat showed lower mean intake of such foods, when compared to those in "pre-action". Likewise, individuals in the stage of action to the reduced intake of red meat reported a diet with lower energy, total fat, and saturated fat intake, nutrients that are present in meat. In addition, individuals in "action" for increased intake of vegetables consumed more of these 
Socio-demographic and lifestyle characteristics of 578 Japanese-Brazilians. Bauru, São Paulo State, Brazil, 2005.

\begin{tabular}{lc}
\hline Characteristics & \\
\hline Second-generation (\%) & 85.3 \\
Mean age in years (SD) & $60(12)$ \\
Female (\%) & 55.2 \\
Working activities (\%) & 48.1 \\
Marital status (\%) & 76.2 \\
Married & 12.8 \\
Widow(er)/Divorced & 11.0 \\
Single & \\
Educational level (\%): & 10.8 \\
$\quad$ None & 45 \\
$\quad<8$ years & 44.2 \\
$\geq 8$ years & \\
Smoking (\%): & 77.2 \\
Never smoked & 15.6 \\
Former smoker & 7.2 \\
Smoker & 21.7 \\
Alcohol consumption (\%) & 91.3 \\
Presence of diseases (\%) * & 63.0 \\
Central obesity (\%) & 43.7 \\
Mean number of meals/day (SD) & $4(1)$ \\
Stage of change for higher intake of vegetables (\%) & 57.0 \\
Stage of change to reduced intake of red meat (\%) & 48.0 \\
\hline
\end{tabular}

SD: standard deviation.

* Presence of diseases: dyslipidemia (National Cholesterol Education Program - NCEP guidelines 15), hypertension (World Health Organization - WHO guidelines 16$)$, and/or diabetes (WHO guidelines $\left.{ }^{14}\right)$.

Tabela 2

Mean intake and standard deviation (SD) for dietary variables according to stages of change for intake of red meat, and vegetables by Japanese-Brazilians. Bauru, São Paulo State, Brazil, 2005.

\begin{tabular}{|c|c|c|c|c|}
\hline & \multicolumn{4}{|c|}{ Stages of change } \\
\hline & \multicolumn{2}{|c|}{ Red meat } & \multicolumn{2}{|c|}{ Vegetables } \\
\hline & $\begin{array}{c}\text { "Pre-action" } \\
(n=303)\end{array}$ & $\begin{array}{l}\text { "Action" } \\
(n=275)\end{array}$ & $\begin{array}{c}\text { "Pre-action" } \\
(n=247)\end{array}$ & $\begin{array}{l}\text { "Action" } \\
(n=331)\end{array}$ \\
\hline \multicolumn{5}{|l|}{ Foods (g/day) } \\
\hline Red meat & $148(122)$ & $109(108)$ * & $142(129)$ & $120(106)$ * \\
\hline Vegetables & $159(87)$ & $176(118)$ & $144(89)$ & $184(110)$ * \\
\hline Fruits & $224(242)$ & $223(181)$ & $205(190)$ & $237(191)$ \\
\hline \multicolumn{5}{|l|}{ Nutrients } \\
\hline Energy (kcal/day) & $2,036(775)$ & $1,833(621)$ * & $2,003(755)$ & $1,892(676)$ \\
\hline Carbohydrates (g/day) & $260(100)$ & $247(79)$ & 259 (95) & $249(88)$ \\
\hline Proteins (g/day) & $90(39)$ & $77(30)$ * & 87 (39) & $82(34)$ \\
\hline Total fat (g/day) & $70(35)$ & $59(26)$ * & $68(36)$ & $62(27)^{\star}$ \\
\hline Saturated fat (g/day) & $20(12)$ & $17(9)$ * & $20(13)$ & $18(9)$ \\
\hline Fiber (g/day) & $23(12)$ & $22(10)$ & $22(12)$ & $22(11)$ \\
\hline
\end{tabular}

* $p<0.05$, unpaired Student's t test, according to stage of change. 
Factors associated with stage of change of action for reduced intake of red meat and increased intake of vegetable by JapaneseBrazilians. Bauru, São Paulo State, Brazil, 2005

\begin{tabular}{|c|c|c|}
\hline \multirow[t]{3}{*}{ Variables } & \multicolumn{2}{|c|}{ Stage of action } \\
\hline & Red meat * & Vegetables * \\
\hline & OR $(95 \% \mathrm{Cl}) * \star$ & OR $(95 \% \mathrm{Cl}) * \star$ \\
\hline \multicolumn{3}{|l|}{ Gender } \\
\hline Male & 1.00 & 1.00 \\
\hline Female & $1.223(0.754 ; 1.984)$ & $1.892(1.154 ; 3.103)$ \\
\hline$p$ trend & 0.41 & 0.012 \\
\hline Age (years) & $1.043(1.02 ; 1.07)$ & $0.992(0.971 ; 1.013)$ \\
\hline$p$ trend & 0.00 & 0.433 \\
\hline \multicolumn{3}{|c|}{ Central obesity according to Japanese population } \\
\hline No & 1.00 & 1.00 \\
\hline Yes & $0.558(0.351 ; 0.887)$ & $0.674(0.426 ; 1.066)$ \\
\hline $\mathrm{p}$ trend & 0.014 & 0.092 \\
\hline \multicolumn{3}{|c|}{$\geq 150$ minutes physical activity/week } \\
\hline No & 1.00 & 1.00 \\
\hline Yes & $1.339(0.897 ; 1.998)$ & $1.001(1.0 ; 1.001)$ \\
\hline $\mathrm{p}$ trend & 0.153 & 0.027 \\
\hline \multicolumn{3}{|c|}{ Intake of red meat } \\
\hline 1st tertile & 1.00 & 1.00 \\
\hline 2nd tertile & $0.660(0.406 ; 1.073)$ & $0.682(0.417 ; 1.115)$ \\
\hline 3rd tertile & $0.497(0.302 ; 0.817)$ & $0.639(0.387 ; 1.054)$ \\
\hline $\mathrm{P}$ trend & 0.006 & 0.08 \\
\hline \multicolumn{3}{|c|}{ Intake of vegetables } \\
\hline 1st tertile & 1.00 & 1.00 \\
\hline $2^{\text {nd }}$ tertile & $0.620(0.377 ; 1.018)$ & $0.971(0.593 ; 1.590)$ \\
\hline 3rd tertile & $0.961(0.592 ; 1.56)$ & $0.957(0.591 ; 1.548)$ \\
\hline$p$ trend & 0.86 & 0.983 \\
\hline
\end{tabular}

* Individuals classified in the stage of action when as compared to pre-action for lower red meat intake and higher intake of vegetables;

** Logistic regression models adjusted for: gender (female/male), generation (1st/2nd), age (years), schooling (none,

$\leq$ complete primary, $\geq$ secondary), marital status (single, married, widow/er, divorced), in the workforce (yes/no), presence of diseases (dyslipidemia, hypertension, and/or diabetes: yes/no), smoking (never smoked, former smoker, current smoker), central obesity (yes/no), $\geq 150$ minutes of physical activity/week (yes/no), number of meals/day, tertile of red meat intake and tertile of intake for vegetables.

foods, as verified by 24-hour recall, compared to those in the "pre-action" stage.

Our data differ from those of previous studies showing that classification of stages of change may not coincide with participants' actual behavior $18,19,20$. According to the latter authors, this instrument provides a subjective classification, whereby some factors can interfere in participants' reports, since objective questions with a pre-determined cutoff (smoking, for example) are answered more easily. Meanwhile, self-reported eating behavior and food intake adequacy are subjective and directly influenced by the individual's interpretation. According to Prochaska et al. ${ }^{21}$, changes during the precontemplation and contemplation stages are conceptualized as the occurrence of alterations in cognitive perception rather than in real behavior, and persons in these stages do not show differences in intake; individuals in the "action" and maintenance stages only differ from each other as to the period in which they adopt the new behavior, thus justifying grouping the stages of change in prior phases ("pre-action": pre-contemplation, contemplation, and preparation) and those subsequent to action ("action": action 
and maintenance) for habit change, as adopted in the current study.

Eating habits are influenced by ethnic and cultural background and various environmental factors, including availability, access, and socioeconomic factors 22 . Food intake changes in an immigrant population indicate cultural adaptation to the current country of residence. Our data suggest that younger individuals are more prone to incorporate new cultural patterns, as demonstrated by poor motivation to the reduced red meat intake (an unusual food in the traditional Japanese diet) 23 .

In the current study, individuals with central obesity showed $40 \%$ lower chance of motivation to the reduced red meat, when compared to normal-weight individuals. Changes in traditional Japanese eating habits associated with the adoption of a sedentary lifestyle have been suggested as the principal determinant of high prevalence of overweight, central obesity, and metabolic alterations in this community. As a hypothesis, the Western diet could explain the unfavorable impact of the environment on body fat deposition and glucose disturbances, as observed in Asian immigrants in the Americas 23. According to Fujimoto et al. 24 some non-Caucasian populations are particularly prone to the development of metabolic syndrome when exposed to the Western lifestyle, given the high genetic susceptibility for weight gain and visceral fat deposition.

The study showed increased motivation to eat more vegetables among women as compared to men. These data agree with previous studies showing increased intake of fruits and vegetables among women as compared to men in the same age bracket $25,26,27,28$. A possible explanation is associated with women's greater knowledge of healthy eating and its relationship to health. Likewise, in Brazilian society women are frequently in charge of purchasing and preparing food, thus favoring the intake of these foods 29,30 . In addition, evidence suggests that compared to women, men assign lower priority to health 31,32 . A study of 1,024 individuals from 55 to 64 years of age participating in the UK Flexible Sigmoidoscopy Screening Trial 33 showed higher consumption of fruits and vegetables (mean of 3.5 portions/ day) among women as compared to men (2.5 portions/day). The study suggests that the main sources of information on nutrition and health are located in settings frequented by women, and that knowledge was directly associated with intake of healthy foods 32 .

The current study showed that physical activity was associated with greater motivation to eat more vegetables. These data agree with the findings from the Native Hawaiian Diabetes Intervention Program, a non-controlled community intervention study of 147 individuals with a family history of diabetes, in which individuals currently practicing physical exercise showed higher odds of being classified in the "action" stage for eating less fat, which can be attributed to their healthier lifestyle 6 .

\section{Conclusion}

On the present study, individual motivation for the higher consumption of vegetable and reduced red meat intake was associated with age, female gender, nutritional status, and physical activity. Among Japanese-Brazilians, more intensive strategies of intervention are needed for males, younger, and sedentary individuals and those with central obesity toward the promotion of motivation and readiness to reach the goals of the lifestyle intervention program.

Our data showed that classification of stages of change for red meat and vegetable intake is a feasible instrument and is consistent with the usual food consumption, and a relevant tool to the establishment of more effective intervention strategies to promote healthy eating behavior change. 


\section{Resumo}

Os estágios de mudança avaliam a motivação individual em alterar hábitos de vida, contribuindo para a elaboração de estratégias de intervenção mais efetivas. O objetivo do presente estudo foi identificar fatores associados aos estágios de mudança para a motivação ao menor consumo de carnes vermelhas e maior consumo de hortaliças em análise transversal conduzida entre 578 nipo-brasileiros, idades entre $30-90$ anos. Em modelos de regressão logística ajustados verificou-se maior odds ratio entre participantes do sexo feminino $(O R=1,89$; IC95\%: 1,154; 3,103) e praticantes de atividades físicas $(O R=1,00$; IC95\%: 1,000; 1,001) para o estágio de "ação" para maior consumo de hortaliças. Verificou-se relação inversa entre presença de obesidade abdominal (OR = 0,56; IC95\%: 0,351; 0,887), maior tercil de consumo de carnes vermelhas $(O R=0,50$; IC95\%: 0,302; 0,817) e associação positiva de idade $(\mathrm{OR}=1,043$; IC95\%: 1,02; 1,07) com o estágio de "ação" para o menor consumo de carnes. A motivação dos nipo-brasileiros para alteração do consumo alimentar estava associada ao estilo de vida dos indivíduos avaliados. Os estágios de mudança são ferramentas eficazes na avaliação da motivação da mudança do consumo alimentar.

Consumo Alimentar; Epidemiologia Nutricional; NipoBrasileiros

\section{References}

1. World Health Organization. The World Health Report 2002: reducing risks, promoting healthy life. Geneva: World Health Organization; 2002.

2. World Health Organization. Diet, nutrition and the prevention of chronic diseases. Report of a Joint WHO/FAO Expert Consultation. Geneva: World Health Organization; 2003. (WHO Technical Report Series, 916).

3. Freire R, Castro T, Cardoso M, Gimeno S, Ferreira S; Japanese-Brazilian Diabetes Study Group. Dietary intakes associated with metabolic syndrome in a cohort of Japanese ancestry. Br J Nutr 2006; 96: 532-8.

\section{Contributors}

D. S. Sartorelli, F. Massimino, R. Damião, M. Bevilacqua, and R. Chain were in charge of coordinating the Nutrition Group and data collection. R. Damião, D. S. Sartorelli, S. R. G. Ferreira, and S. G. A. Gimeno were responsible for the study design and coordinating the data collection. D. S. Sartorelli, P. Barbieri, R. F. M. Palma, and R. Y. Nishimura were responsible for the analysis and interpretation of the results. P. Barbieri and D. S. Sartorelli wrote the manuscript. All the authors revised and contributed to the final version.

\section{Other members of the Japanese-Brazilian Diabetes Study Group}

Alcides Hirai, Amélia T. Hirai, Helena Harima, Magid Iunes (in memoriam), Mário Kikuchi, Katsumi Osiro, Katsunori Wakisaka, Laércio J. Franco, Marly Augusto Cardoso, Nilce Tomita, Newton de Barros Junior, Regina C. S. Moisés, Luiza Matsumura, and Vania D'Almeida.

\section{Acknowledgments}

The authors wish to thank the São Paulo State Research Foundation (FAPESP; 2005/59178-7) and Brazilian National Research Council (CNPq; 505845/2004-0) for their financial support. P. Barbieri held a scientific initiation scholarship from the Teaching and Research Program of the University of São Paulo and FAPESP. R. F. M. Palma held a scientific initiation scholarship from CNPq, and R. Y. Nishimura held a scientific initiation scholarship from FAPESP.

4. Sartorelli DS, Freire RD, Ferreira SR, Cardoso MA Japanese-Brazilian Diabetes Study Group. Dietary fiber and glucose tolerance in Japanese Brazilians. Diabetes Care 2005; 28:2240-2.

5. Pinheiro ARO, Gentil PC. A iniciativa de incentivo ao consumo de frutas, legumes e verduras no Brasil: documento-base. Brasília: Ministério da Saúde; 2004.

6. Mau MK, Glanz K, Severino R, Grove JS, Johnson B, Curb JD. Mediators of lifestyle behavior change in native Hawaiians. Diabetes Care 2001; 24:1170-5.

7. Kristal AR, Glanz K, Curry SJ, Patterson RE. How can stages of change be best used in dietary interventions? J Am Diet Assoc 1999; 99:679-84. 
8. Kristal AR, Glanz K, Tilley BC SJ, Li S. Mediating factors in dietary change: understanding the impact of a worksite nutrition intervention. Health Educ Behav 2000; 27:112-25.

9. Gimeno SGA, Ferreira SRG, Franco LJ, Hirai AT, Matsumura L, Moisés RS. Prevalence and 7-year incidence of type II diabetes mellitus in a Japanese-Brazilian population: an alarming public health problem. Diabetologia 2003; 45:1635-8.

10. Craig CL, Marshall AL, Sjöström M, Bauman AE, Booth ML, Ainsworth BE, et al. International physical activity questionnaire: 12-country reliability and validity. Med Sci Sports Exerc 2003; 35: 1381-95.

11. Núcleo de Estudos e Pesquisas em Alimentação, Universidade Estadual de Campinas. Tabela brasileira de composição de alimentos - TACO, versão 2. 2a Ed. Campinas: Núcleo de Estudos e Pesquisas em Alimentação, Universidade estadual de Campinas; 2006.

12. Tomita LY, Cardoso MA. Relação de medidas caseiras, composição química e receitas de alimentos nipo-brasileiros. São Paulo: Editora Metha; 2002.

13. Alberti KG, Zimmet PZ. Definition, diagnosis and classification of diabetes mellitus and its complications. Part 1: diagnosis and classification of diabetes mellitus provisional report of a WHO consultation. Diabet Med 1998; 15:539-53.

14. Expert Panel on Detection, Evaluation, and Treatment of High Blood Cholesterol in Adults. Executive Summary of the Third Report of the National Cholesterol Education Program (NCEP) Expert Panel on Detection, Evaluation, and Treatment of High Blood Cholesterol in Adults (Adult Treatment Panel III). JAMA 2001; 285:2486-97.

15. World Health Organization. Hypertension control: report of a WHO expert committee. Geneva: World Health Organization; 1996. (WHO Technical Report Series, 862).

16. World Health Organization. Steering Committee of the Western Pacific Region of the WHO, the International Association for the Study of Obesity, and the International Obesity Task Force. The Asia-Pacific perspective: redefining obesity and its treatment. Geneva: World Health Organization; 2000.

17. Instituto Brasileiro de Geografia e Estatística. Pesquisa de Orçamentos Familiares 2002-2003: análises da disponibilidade domiciliar de alimentos e do estado nutricional no Brasil. Rio de Janeiro: Instituto Brasileiro de Geografia e Estatística; 2004.

18. Bowen DJ, Meisechke H, Tomoyasu N. Preliminary evaluation of the processes of changing to a lowfat diet. Health Educ Res 1994; 9:85-94.
19. Sigman-Grant M. Stages of change: a framework for nutrition interventions. Nutr Today 1996; 31:162-70.

20. Ni Mhurchu C, Margetts BM, Speller VM. Applying the stages-of-change model to dietary change. Nutr Rev 1997; 55(1 Pt 1):10-6.

21. Prochaska JO, Redding C, Evers K. The transtheoretical model of behavior change. In: Glanz K, Lewis FM, Rimer BK, editors. Health behavior and health education: theory, research and practice. San Francisco: Jossey-Bass Inc.; 1997. p. 60-84.

22. Jacques PF, Turcker KL. Are dietary patterns useful for understanding the role of diet in chronic disease? Am J Clin Nutr 2001; 73:1-2.

23. Cardoso MA, Hamada GS, Souza JMP, Tsugane S, Tokudome S. Dietary patterns in Japanese migrants to southeastern Brazil and their descendants. J Epidemiol 1997; 7:198-204.

24. Fujimoto WY, Begstrom RW, Boyko EJ, Leonetti DL, Newell-Morris LL, Wahl PW. Susceptibility to development of central adiposity among populations. Obes Res 1995; 3 Suppl 2:179-86.

25. Wardle J, Parmenter K, Waller J. Nutrition knowledge and food intake. Appetite 2000; 34:269-75.

26. Trudeau E, Kristal A, Li S, Patterson RE. Demographic and psychosocial predictors of fruit and vegetable intakes differ: implications for dietary interventions. J Am Diet Assoc 1998; 98:1412-7.

27. Jaime PC, Monteiro CA. Fruit and vegetable intake by Brazilian adults, 2003. Cad Saúde Pública 2005; 21 Suppl 1:S19-24.

28. Davy SR, Benes BA, Driskell JA. Sex differences in dieting trends, eating habits and nutrition beliefs of a group of Midwestern College Students. J Am Diet Assoc 2006; 106:1673-7.

29. Courtenay WH, McCreary DR, Merighi JR. Gender and ethnic differences in health beliefs and behaviours. J Health Psychol 2002; 7:219-31.

30. Fagerli RA, Wandel M. Gender differences in opinions and practices with regard to a "healthy diet". Appetite 1999; 32:171-90.

31. Furnham A, Kirkaldy B. Age and sex differences in health beliefs and behaviours. Psychol Rep 1997; 80:63-6.

32. UK Flexible Sigmoidoscopy Screening Trial Investigators. Single flexible sigmoidoscopy screening to prevent colorectal cancer: baseline findings of a UK multicentre randomized trial. Lancet 2002; 359:1291-300.

33. Baker AH, Wardle J. Sex differences in fruit and vegetable intake in older adults. Appetite 2003; 40:269-75.

Submitted on 17/Mar/2008

Final version resubmitted on 08/Jul/2008

Approved on 24/Jul/2008 